\title{
Observations of the dynamic structure of snow avalanches
}

\author{
K. Nishimura, N. MaEno, \\ Institute of Low Temperature Science, Hokkaido University, Sapporo 060, Japan \\ F. Sandersen, K. Kristensen, H. Norem and K. Lied \\ Norwegian Geotechnical Institute, Tasen N-0801, Oslo, Norway
}

\begin{abstract}
During two winters, 1990-92, the dynamic structures of snow avalanches were studied in western Norway. Artificially released wet-snow avalanches ran down the avalanche chute and stopped in front of the retaining dam. Running velocity distributions were obtained not only by video tape recorder, but also by various other recording instruments. Internal velocity was derived for the last avalanche by frequency analysis of impact pressure and optical sensor data. The vertical velocity shear of the avalanche flow has been estimated to be in the range $1-$ $10 \mathrm{~s}^{-1}$.
\end{abstract}

\section{INTRODUCTION}

In spite of long and sustained efforts to reveal the structure and behavior of snow avalanches, reliable data obtained so far are still inadequate. Especially lacking are those data associated with the internal and dynamic structures. In the winters of 1990-91 and 1991-92 a Japanese-Norwegian joint project was undertaken which aimed to collect such data related to the dynamic structures of snow avalanches. The experimental site, Ryggfonn, is located near a field research station in Glasdalen, western Norway, where the Norwegian Geotechnical Institute (NGI) has carried out full-scale avalanche experiments since 1981 .

Large flowing avalanches did not occur during the observation periods, when the climate was rather mild. But on 20 March 1991 and on 20 May 1992, artificially released avalanches ran down the avalanche chute and reached the dam, and various data were obtained. This paper reports those two avalanches and gives some results of the preliminary analysis.

\section{MEASUREMENTS}

The avalanches released artificially in Ryggfonn start at $1530 \mathrm{~m}$ a.s.l. and run down some $1600 \mathrm{~m}$ on an avalanche path of $28^{\circ}$ mean slope (Fig. 1). The vertical drop is about $900 \mathrm{~m}$. A retaining dam $15 \mathrm{~m}$ high and $75 \mathrm{~m}$ wide has been constructed in the avalanche runout zone, and a steel mast $6.5 \mathrm{~m}$ in height erected on it. Above the dam, $230 \mathrm{~m}$ up the avalanche path, is a concrete structure $4.5 \mathrm{~m}$ high and $0.6 \mathrm{~m}$ wide. The impact pressures of the avalanche are measured by three load cells. A further $320 \mathrm{~m}$ upslope from the dam is a tubular steel tower $10 \mathrm{~m}$ high and $1.3 \mathrm{~m}$ in diameter, on which strain gauges for measuring shear and moment forces, mechanical pressure indicators and a geophone were mounted. More detailed information of the measurement system has been reported by Norem and others (1985).

In addition to these instruments, the following were set up in the winter 1990-91: one video camera installed in front of the avalanche path and one near the instrument hut; an ultrasonic anemometer on top of the dam tower; a seismograph on the dam; an air-pressure sensor on the dam. Furthermore, for the purpose of investigating the internal structures of the avalanche, additional sensors were set in the winter 1991-92. Figure 2 shows a new measuring apparatus mounted on the tubular tower (small impact-pressure sensors mounted

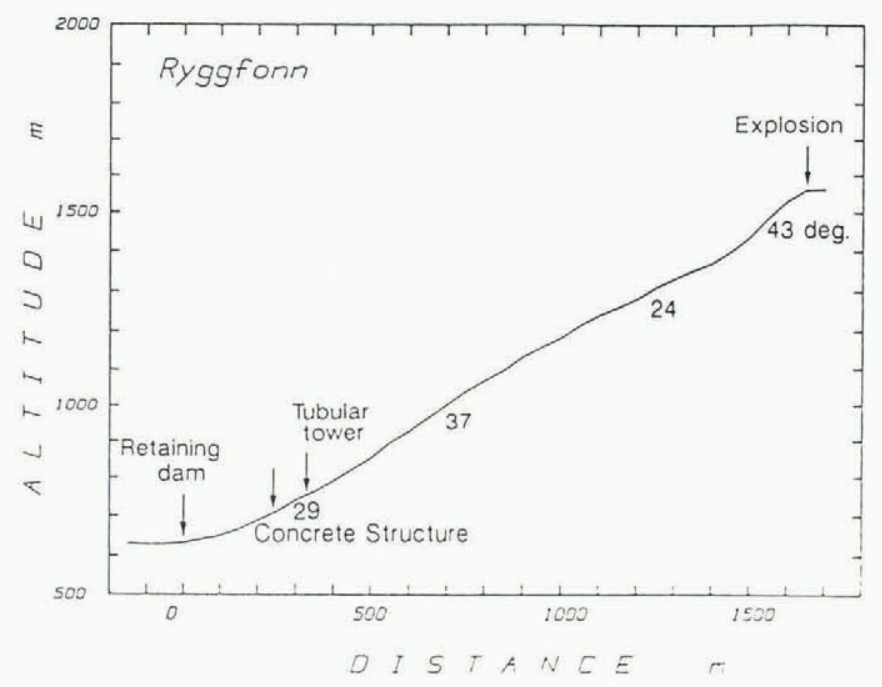

Fig. 1. Cross-section of the Ryggfonn avalanche path. 


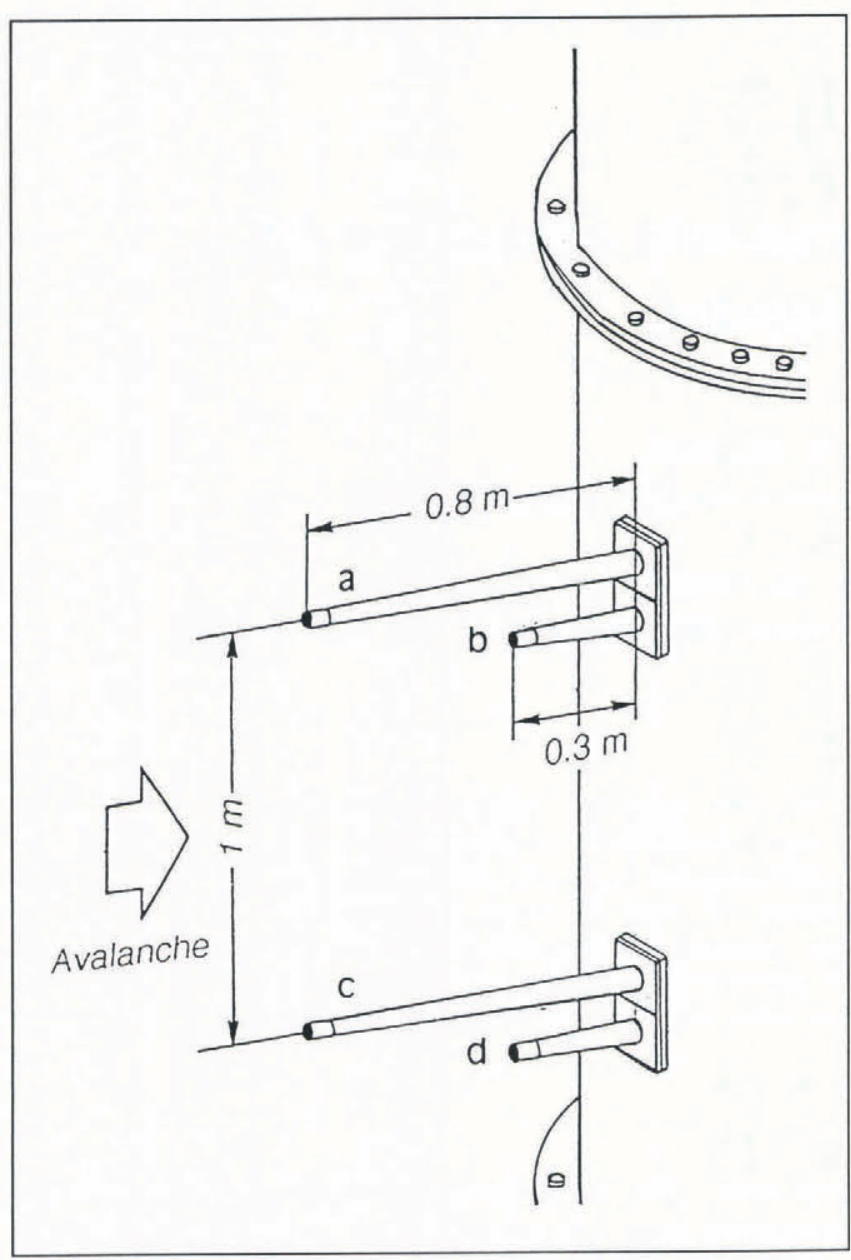

Fig. 2. Schematic representation of the impact-pressure sensors $(a-d)$ set on the tubular tower.

with the horizontal distance of $50 \mathrm{~cm}$ ). Figure 3 shows an apparatus on the concrete structure comprising small impact-pressure sensors with the distance of $50 \mathrm{~cm}$ and optical sensors, which measure the reflectivity of light and obtain density variation as well as internal velocity.

\section{RESULTS}

\section{Avalanche on 20 March 1991}

This avalanche was artificially released by $100 \mathrm{~kg}$ of explosives preplanted in the cornice. It ran down the avalanche track and stopped just in front of the dam. Only a small snow cloud was generated by the avalanche, and it disappeared at the same position as the dense part of the avalanche stopped. After the stop of the front of the avalanche, the avalanching snow kept running towards the concrete structure for approximately $1 \mathrm{~min}$ and gradually increased the horizontal width of the avalanche deposit.

The seismograph on top of the dam recorded both the time of explosion and the main vibration, which is assumed to correspond to the time when the avalanche hit the front of the dam (Fig. 4). This time difference is $69 \mathrm{~s}$, which gives an average velocity of $22 \mathrm{~m} \mathrm{~s}^{-1}$. The avalanche-front velocities, estimated by analyzing the video tapes and the hitting time of different sensors, are given in Figure 5. Velocities obtained both by video tapes and other instruments showed good agreement. The velocity of the avalanche was over $25 \mathrm{~m} \mathrm{~s}^{-1}$ in the construction area, and decreased to about $20 \mathrm{~m} \mathrm{~s}^{-1}$ in front of the dam. The video and other recordings indicated that the front velocity had only a minor reduction before the avalanche stopped suddenly in front of the dam. The highest impact pressure on the load cell was $320 \mathrm{kPa}$, and the maximum shear and moment at the steel tower were $1149 \mathrm{kN}$ and $3250 \mathrm{kNm}$ respectively. The recordings of the ultrasonic anemometer on top of the dam did not show any distinct signals. Some

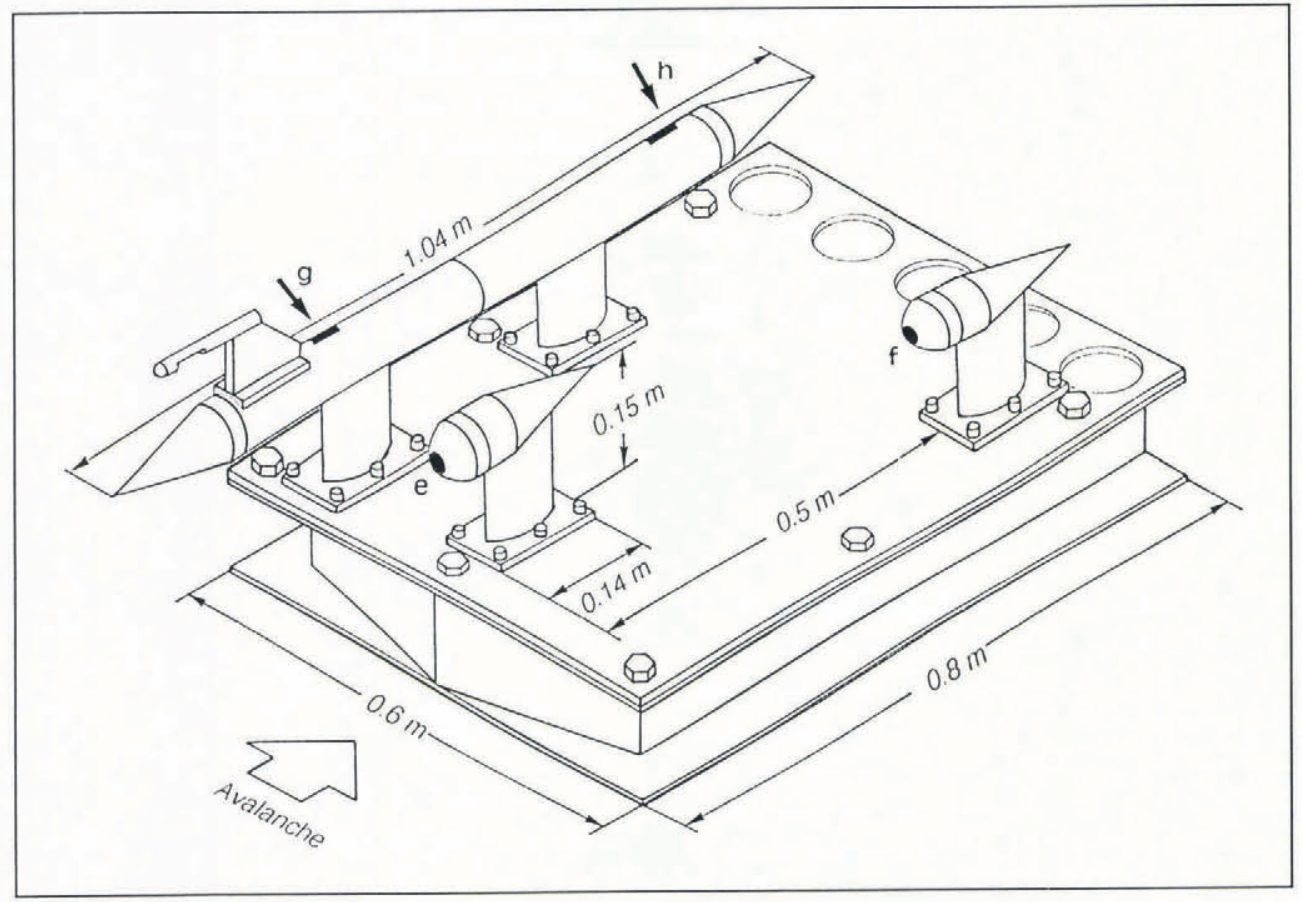

Fig. 3. Schematic representation of the measuring apparatus set on the concrete structure. $e$ and $f$, impact pressure sensors; $g$ and $h$, optical sensors. 


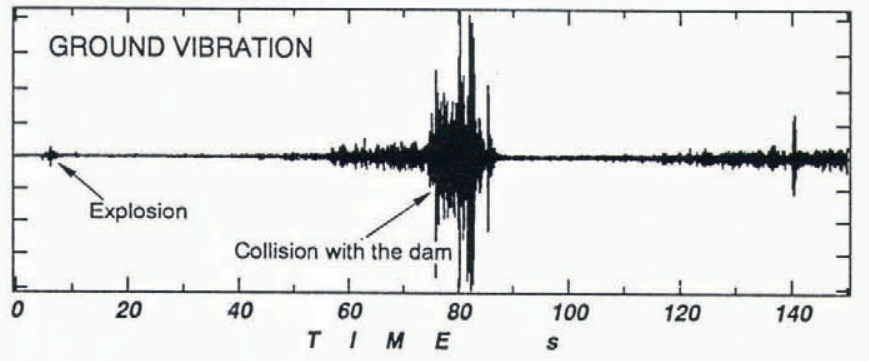

Fig. 4. Recording of ground vibration during the avalanche on 20 March 1991.

of these data have been reported by Norem and others (1991).

The volume of the avalanche deposit was estimated to be approximately $15000 \mathrm{~m}^{3}$ with a maximum thickness of about $5 \mathrm{~m}$. The avalanche deposit consisted of wet snow balls, having a diameter ranging between 0.05 and $0.3 \mathrm{~m}$ on the top surface.

\section{Avalanche on 20 May 1992}

This avalanche was released by detonating $50 \mathrm{~kg}$ of dynamite placed on the snow surface in the starting zone. It was a wet-snow avalanche and its velocity was much slower than that of 20 March 1991. The snow in the first part of the avalanche seemed to stop after passing the concrete structure, but the following part had enough velocity to reach about $30 \mathrm{~m}$ in front of the dam. The avalanche debris was composed of wet snow balls. Figure 6 shows recordings of the impact pressures on the tower (A) and the concrete structure (C), and the light reflectivity (B) measured by an optical sensor set on the concrete structure .

The first impact on the tower was observed at $1 \mathrm{~s}$ and lasted for $2 \mathrm{~s}$ (Fig. 6A). In the following $20 \mathrm{~s}$ only spikes caused by the impact of snow balls are seen. At $24 \mathrm{~s}$ a dense flow considered to be a mixture of snow balls and fluidized snow reached the tower and showed high impact pressures. On the other hand, the front of the flow arrived at the concrete structure at 9-10s (Fig. 6B and C). Both light reflectivity, which is a measure of the relativedensity variation, and impact pressure showed rather low signals until $32 \mathrm{~s}$. The high impact pressure was found about $23 \mathrm{~s}$ after the first impact, which seemed to correspond to the arrival of the dense flow.

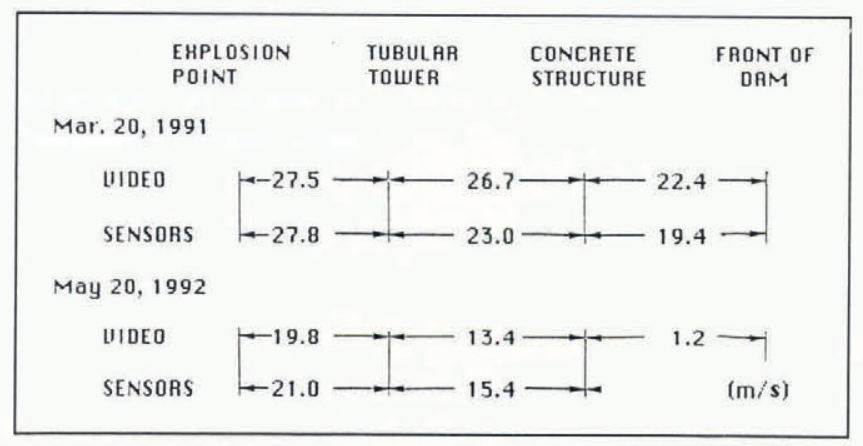

Fig. 5. Front velocity of the avalanches estimated from the video-tapes and the recordings from the sensors.
Front velocities calculated with the video and other recordings, which are given in Figure 5, agreed well with each other. It is conjectured that the velocity exceeded about $20 \mathrm{~m} \mathrm{~s}^{-1}$ near the tower but was less in the construction area. In particular, it flowed very slowly from the concrete structure to the dam area. No snow clouds developed, nor did the recordings of the ultrasonic anemometer on top of the dam show any distinct variations.

\section{DISGUSSION AND CONGLUSIONS}

The data of impact pressure and light reflectivity recorded by means of the analogue data-recorder were transformed into digital values using an $\mathrm{A}-\mathrm{D}$ converter
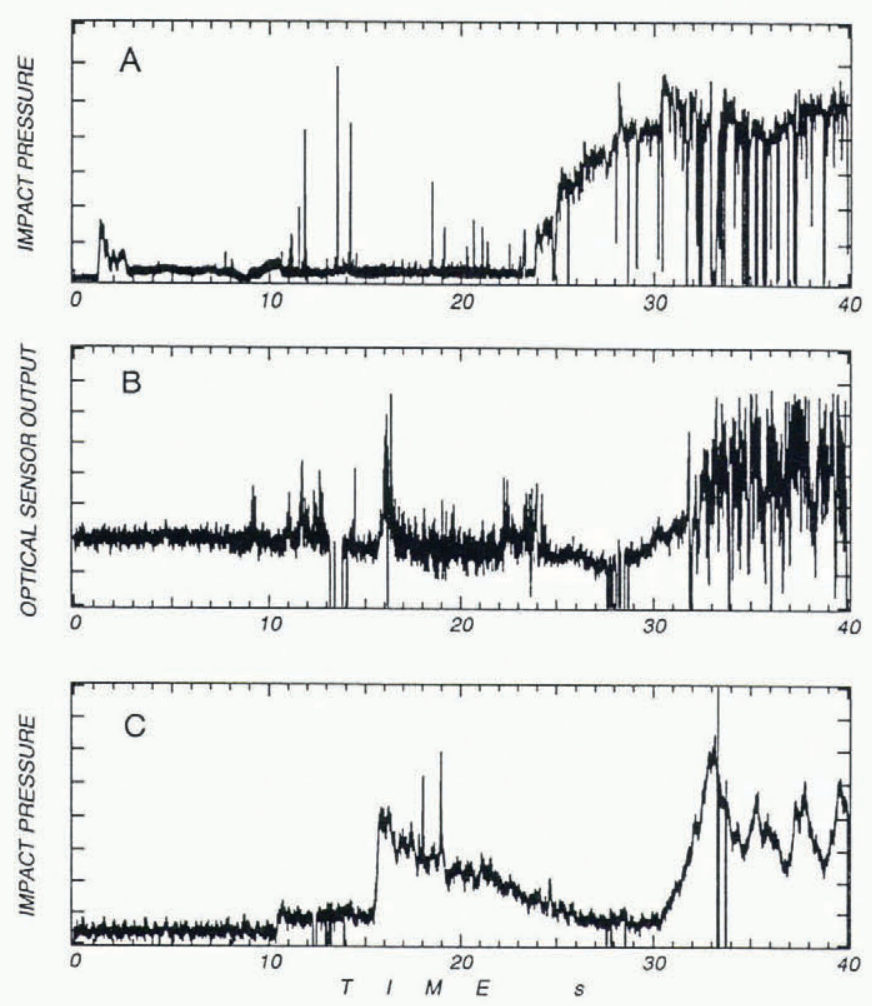

Fig. 6. Recordings obtained during the passage of the avalanche on 20 May 1992. The units of the vertical axes are arbitrary. $A$, impact pressure on the tower ( $d$ in Fig. 2 ); $B$, light reflectivity on the concrete structure ( $g$ in Fig. 3); $C$, impact pressure on the concrete structure (measuring plate area is $0.6 \times 1.2 \mathrm{~m}^{2}$ ).

and a cross-correlation function was calculated for various pairs of the data. The average internal velocity was obtained from a combination of the lag time that gave the highest correlation and the distance between the two measuring points. Further details of the analysis method have been given in Nishimura and others (1987). Calculated results for pairs of impact pressure data on the tower $(\mathrm{a}-\mathrm{b}$ and $\mathrm{c}-\mathrm{d})$ are presented in Figure 7 . Time in the figure is the same as that in Figure 6. The internal velocity about $4 \mathrm{~s}$ after the avalanche front passed became fairly slow relative to the front velocity shown in Figure 5. The maximum velocity appeared at $24 \mathrm{~s}$, when the dense 


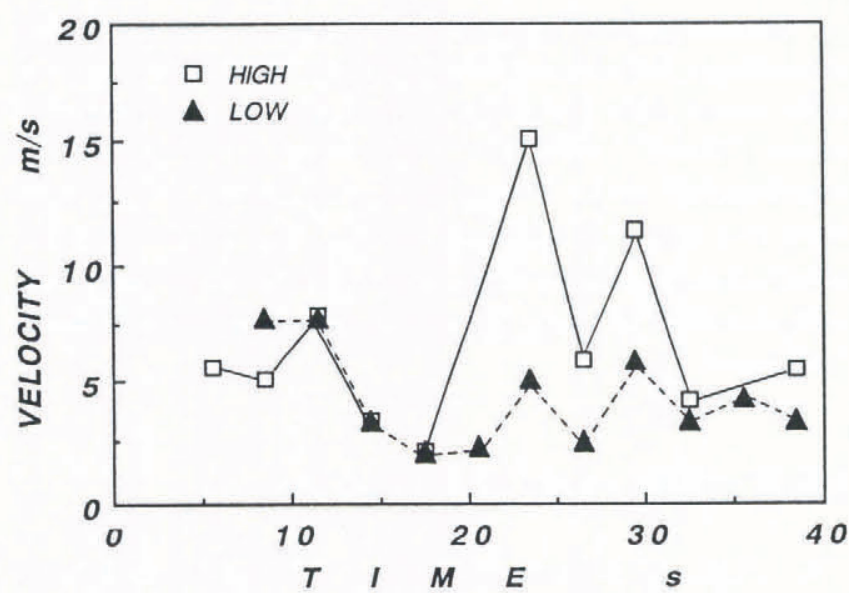

Fig. 7. Internal velocity of the avalanche on 20 May 1992. Squares and triangles refer to the velocities calculated from the pair recordings of impact pressures, $a$ and $b$, and $c$ and d, respectively (Fig. 2).

part of the flow arrived. We may reasonably conclude that the impact pressure peaked at $23 \mathrm{~s}$ after the passage of the front, because of not only the high density but also the high velocity.

The internal velocity in the high position was generally faster than that in the low position, and was particularly distinct in the dense flow region. Taking into account the vertical distance of $1 \mathrm{~m}$ between each set of impact-pressure sensors, the vertical velocity shear of the avalanche has been estimated to be in the range of 1$10 \mathrm{~s}^{-1}$. This value is a significant parameter in the avalanche dynamics (Nishimura, 1990) and the value obtained here agrees well with that of $1-7 \mathrm{~s}^{-1}$ in the Kurobe Canyon (Nishimura and others, 1989). Internal velocities at the concrete structure are shown in Figure 8. Calculated velocities from the recordings of impact pressures (e and $\mathrm{f}$ in Figure 3 ) roughly agree with those obtained from recordings of optical sensor output ( $g$ and h).

\section{ACKNOWLEDGEMENTS}

This Norwegian-Japanese collaboration has been made possible by financial support from the International Scientific Research Program of the Ministry of Education, Science and Culture, Japan, and from the Royal Norwegian Council for Scientific and Industrial Research. The observation at Ryggfonn was carried out with the helpful collaboration of the following members: K. Izumi (Research Institute for Hazards in Snowy Areas, Niigata University), K. Kawada (Toyama University),

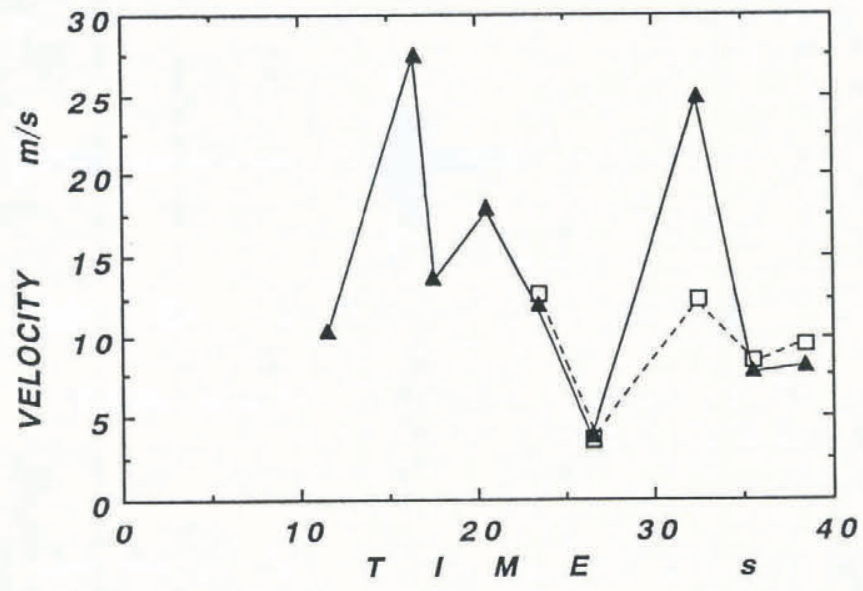

Fig. 8. Internal velocity of the avalanche on 20 May 1992. Squares refer to the velocities calculated from the recordings of impact pressures ( $e$ and $f$ in Fig. 3), and triangles to those calculated from recordings of optical sensor output ( $g$ and $h$ ).

H. Iida (Yoshida Science Museum of Kurobe City), Y. Nohguchi and O. Abe (National Research Institute of Earth Science and Disaster Prevention), T. Fukuzawa and S. Nakatsubo (Institute of Low Temperature Science, Hokkaido University), M. Nakagawa (Tohoku University), R. Kimura (Ocean Research Institute, Tokyo University).

\section{REFERENCES}

Nishimura, K. 1990. Studies on the fluidized snow dynamics. Contrib. Inst. Low Temp. Sci., Series A 37.

Nishimura, K., N. Maeno and K. Kawada. 1987. Internal structures of large-scale avalanches revealed by a frequency analysis of impact forces. Low Temp. Sci., Ser. A 46, 91-98. (In Japanese with English summary.)

Nishimura K., H. Narita, N. Maeno and K. Kawada. 1989. The internal structure of powder-snow avalanches. Ann. Glaciol., 13, 207-210.

Norem, H., T. Kvisterøy and B.D. Evensen. 1985. Measurement of avalanche speeds and forces: instrumentation and preliminary results of the Ryggfonn Project. Ann. Glaciol., 6, 19-22.

Norem, H., K. Kristensen and K. Tronstad. 1991. The Ryggfonn Project. Avalanche data from the 1990/1991 winter. Oslo, Norges Geotekniske Institutt. (NGI-Report 581200-24.)

The accuracy of references in the text and in this list is the responsibility of the authors, to whom queries should be addressed. 